\title{
Residue and Risk Assessment of Kresoxim-methyl in Apple Under Field Conditions
}

\author{
Qian Xun, Chen Yong-da, Zheng Zhen-shan, Wang Li, Zhang Shao-jun* \\ Research Centre of Quality and Safety of Agro-products, Hebei Academy of Agriculture and Forestry Sciences, Shijiazhuang, China
}

\section{Email address:}

Xunqian1968@sina.com (Qian Xun), zhangshj601@163.com (Zhang Shao-jun)

${ }^{*}$ Corresponding author

\section{To cite this article:}

Qian Xun, Chen Yong-da, Zheng Zhen-shan, Wang Li, Zhang Shao-jun. Residue and Risk Assessment of Kresoxim-methyl in Apple Under Field Conditions. International Journal of Nutrition and Food Sciences. Vol. 5, No. 4, 2016, pp. 293-196. doi: 10.11648/j.ijnfs.20160504.19

Received: June 30, 2016; Accepted: July 1, 2016; Published: July 20, 2016

\begin{abstract}
A rapid and effective method was developed for determination of kresoxim-methyl residue in apple. Field trials were designed to evaluate the dissipation and residue of kresoxim-methyl in apple at Hebei (China), Shandong (China) and Anhui (China). The dietary exposure and risk assessment were also conducted by using the calculation of risk quotient (RQ). The samples were extracted by Acetone and ethyl acetate, cleaned up by Florisil solid phase extraction column and detected by gas chromatograph with DB-1701 capillary column and electron capture detector. The results showed good average recoveries of $80 \%-99 \%$ with relative standard deviations of $0.9 \%-1.3 \%$ at the spiked level of $0.02,0.20$ and $2.0 \mathrm{mg} / \mathrm{kg}$. The limit of detection (LOD) was $1.0 \times 10^{-12} \mathrm{~g}$ and the limit of quantification (LOQ) was $0.02 \mathrm{mg} / \mathrm{kg}$. The results were found that the half lives of kresoxim-methly in apple of Hebei (China), Shandong (China) and Anhui (China) were 6.09, 12.6 and $10.0 \mathrm{~d}$ respectively, and the terminal residue was below MRL $(0.2 \mathrm{mg} / \mathrm{kg}) 14$ days after application, the RQ of kresoxim-methyl were far below 1 . It predicted that it was safe for human being when kresoxim-methyl was used to control Apple tree diseases.
\end{abstract}

Keywords: Kresoxim-methyl, Apple, Residue, Risk Assessment

\section{Introduction}

Kresoxim-methyl is a kind of methacrylic acid ester antiseptic, it acts as a mitochondrial respiratory inhibitor. By transferring the electrons between the cytochromes, it inhibits the respiration of mitochondrial and destroys the energy synthesis in order to act as a bactericide. It is able to prevent from invading of the pathogenic spore and it can effectively inhibit the germination of the spore and the development of the leaves of mycelium. It is widely used on early blight of tomato, powdery mildew of strawberry and cucumber, venturia pirina, ring rot of apple and Powdery mildew spot and leaf spot etc [1-4]. According to European Food Safety Authority, 2010 [5], the ADI (Acceptable Daily Intake) value of kresoxim-methyl is $0.4 \mathrm{mg} / \mathrm{kg}$ bw. China's Nation Standard GB 2763-2014 "National food safety standard - Maximum residue limits for pesticides in food" has stipulated that the MRL (Maximum Residue Limit) value of an apple should be $0.2 \mathrm{mg} / \mathrm{kg}$.

Currently, the method of calibration of kresoxim-methyl pesticide including separation and quantification using high performance liquid chromatography (HPLC) with UVdetector [6-7] or using gas chromatography with flame ionization detector (FID) [8]. Residual quantity analysis method is commonly used on growing plants of rice, wheat, cucumber, strawberry and apple etc., the residues analysis of kresoxim-methyl in grain harvestry, fruits and soil as well as the study of the degradation pattern [9-15]. Ge etc. [9-11] have used gas chromatography electron capture detector (ECD) to detect and analyze the residue of kresoxim-methyl in cucumber and soil, and they studied the pattern of degradation dynamics of kresoxim-methyl on cucumber. Liu Congyun [12] and his team have adopted the LC - MS method to detect the kresoxim-methyl residue of cucumber and at the same time completed the dietary risk assessment of kresoxim-methyl in cucumber. Yu Xueli [13-15] and her team have used the gas chromatography electron capture detector (ECD) to detect the residue of kresoxim-methyl in wheat, rice and soil.

In this research, the extract of apple sample was purified with florisil SPE column. A method to detect the residue of 
kresoxim-methyl in apple was developed by using gas chromatography capillary column to separate and using electron capture detector (ECD) to detect. The method was used to study the degradation dynamics and the final residue of $40 \%$ kresoxim-methyl deflocculant of apple fields in different areas in China, at the same time, calculated the dietary exposure of pesticide and perform the risk assessment of the detection result of sample residues.

\section{Materials and Method}

\subsection{Agentia and Apparatus}

Standard substance of kresoxim-methyl (99.0\%) provided by the National pesticide products quality supervision and Inspection Center, china; 40\% kresoxim-methyl SC provided by Jiangxi Zhengbang biological chemical Limited by Share Ltd (China); Sodium chloride, anhydrous sodium sulfate (analytical reagent AR) provided by Tianjin concord technology co., Ltd (China); Ethyl acetate, acetone, hexane (chromatographic pure) provided by Fisher U.S.; SPE-Florisil column (1 g, $6 \mathrm{~mL})$ provided by Supelco (USA).

Gas chromatograph (Shimadzu GC 2010 plus, Shimadzu, Japan), with electron capture detector and chromatography workstation; homogenizer (T25, IKA German); solid phase extraction apparatus (Beijing KangLin Technology Co., Ltd., China); nitrogen blowing instrument (DCY-24S Qingdao Haike instrument Co., Ltd.)

\subsection{Field Testing}

The experiment was carried out in Shijiazhuang, Hebei province, China; Yantai, Shandong province, China; Suzhou, Anhui province, China. 40\% kresoxim-methyl SC was used for testing.

\subsubsection{Digestion Dynamic Test}

To investigate the dissipation of kresoxim-methyl in plant, apples were sprayed with kresoxim-methyl formulation (40\% SC) of the dosage of $300 \mathrm{mg}$ a.i. $/ \mathrm{kg}$. Three areas were set to repeat experiment and put 2 trees in each area. Areas are equipped with isolation belt, and compared areas were also set. The pesticide was sprayed when apples in the trees had a diameter of $3 \mathrm{~cm}$ and perform sample collection $1 \mathrm{~h}$, and 1, 3, 5, 7, 14, 21, 30, 45 days after spraying. Afterwards, The content of kresoxim-methyl in the apple samples was determined using the method developed earlier.

\subsubsection{Final Residue Test}

Low dosage (200 mg a.i. $/ \mathrm{kg}$ ) and high dosage (300 mg a.i. $/ \mathrm{kg}$ ) of the pesticide was applied 3 and 4 times respectively in an interval of 7 days. Three areas were set to repeat experiment and 2 trees in each area. In addition, A blank region was set for comparison. The pesticide was sprayed when apples in the trees had a diameter of $3 \mathrm{~cm}$ and perform sample collection 14, 21 and 28 days after spraying. The content of kresoxim-methyl was Determined.

\subsection{Preparation of the Sample}

\subsubsection{Extraction}

$25.0 \mathrm{~g}$ of sample, exact $40 \mathrm{ml}$ of acetone and $60 \mathrm{~mL}$ of ethyl acetate was broke up with a homogenate machine, after that operate ultrasonic oscillation for 5 mins. Put them aside until the layers are completely separated. Transfer the upper layer into a $100 \mathrm{~mL}$ stopper measuring cylinder which contains $5 \mathrm{~g}$ of sodium chloride, continue shaking it for $1 \mathrm{~min}$ and put it aside for another $10 \mathrm{~min}$. When the layers were completely separated, collect $50 \mathrm{ml}$ of the upper layer liquid, transfer it through anhydrous sodium sulfate and wash it using a small amount of acetone. Perform vacuum steam at 45 degrees Celsius to nearly dry and add $3 \mathrm{ml}$ of n-hexane and carry on to nearly dry. Dissolve the residue into $2 \mathrm{ml}$ of $\mathrm{n}$-hexane and purify it with florisil column.

\subsubsection{Purification}

Wash the florisil column with $5 \mathrm{~mL}$ of acetone / hexane $(20: 80, v / v)$ and $5 \mathrm{~mL}$ of hexane, filter the washing liquid and when the liquid level is lower than the surface of the infilling, fill the column with the sample liquid and dispose it. After that use $10 \mathrm{~mL}$ of acetone / hexane $(20: 80, v / v)$ to wash the beaker in two times and fill the column with the sample liquid. Collect the elution liquid and blow it with nitrogen at 40 degrees Celsius to nearly dry and ethyl acetate was used to make it up to $5 \mathrm{ml}$.

\subsection{Chromatography Condition}

Chromatography column: DB-1701 (30 $\mathrm{m} \times 0.25 \mathrm{~mm} \times 0.25$ $\mu \mathrm{m}$, Agilent Technologies); column temperature: keep it at $80^{\circ} \mathrm{C}$ for $1 \mathrm{~min}$ and increase the temperature to $260^{\circ} \mathrm{C}$ with a speed of $20^{\circ} \mathrm{C} / \mathrm{min}$, and keep this temperature for $5.5 \mathrm{~min}$; Inlet temperature: $250^{\circ} \mathrm{C}$, perform shunt injection with a split ratio of 10; Detector temperature: $300^{\circ} \mathrm{C}$; Carrier gas: $\mathrm{N} 2$ (99.999\%); Flux: $2.0 \mathrm{~mL} / \mathrm{min}$; Tail blowing: $30 \mathrm{~mL} / \mathrm{min}$; Sample size: $1.0 \mu \mathrm{L}$.

Under the above chromatography condition, retention time: kresoxim-methyl 11.4 min.

\subsection{Risk Assessment}

Use equation (1) and (2) to calculate Dietary exposure of pesticide and perform risk assessment [16]

$$
\begin{aligned}
& \operatorname{EED}(\mathrm{mg} / \mathrm{kg} \mathrm{bw})=\mathrm{CRL}(\mathrm{mg} / \mathrm{kg}) \times \mathrm{FI}(\mathrm{kg}) \div \mathrm{bw}(\mathrm{kg}) \\
& \mathrm{RQ}=\operatorname{EED}(\mathrm{mg} / \mathrm{kg} \mathrm{bw}) \div \mathrm{ADI}(\mathrm{mg} / \mathrm{kg} \mathrm{bw})
\end{aligned}
$$

Where:

In equation (1): EED is estimated exposure dose

CRL is calculated residue level

FI is Food intake (refers to table 1)

In equation (2): bw is Body weight

RQ is Risk quotient

ADI is acceptable daily intake

When the risk quotient $(\mathrm{RQ})>1$, a high risk which is not acceptable exists, the higher the RQ the more the risk; when $\mathrm{RQ}<1$, the risk detected is acceptable, the lower the RQ, the 
lesser the risk [16].

Table 1. Body weight and fruit intake of different crowds [17].

\begin{tabular}{lll}
\hline Crowd & Body weight/kg & Fruit intake/[g/(person·d)] \\
\hline Age 2-4 boy & 14.1 & 43.7 \\
Age 2-4 girl & 13.4 & 44.4 \\
Male age 18-30 & 60.5 & 41.8 \\
Female age 18-30 & 52.6 & 52.9 \\
Male age 60-70 & 61.3 & 33.8 \\
Female age 60-70 & 54.3 & 34.8 \\
\hline
\end{tabular}

\section{Results and Analysis}

\subsection{Linearity Range and Detection Limit}

Acetic ether was used as the solvent to prepare the standard solution of kresoxim-methyl of $100 \mu \mathrm{g} / \mathrm{mL}$, and the solution was diluted into $0.01,0.05,0.1,1.0,2.0,5.0 \mu \mathrm{g} / \mathrm{mL}$ series of standard solutions. Under the above instrument condition, the series of standard solutions were detected and graphs were constructed of the peaks on standard solution concentration $(\mu \mathrm{g} / \mathrm{mL})$ while drawing standard working curves for kresoxim-methyl. The linear equation of kresoxim-methyl is
$Y=258536 X+25866$, the correlation coefficient $r=0.9992$ where $Y$ is the peak area, $X$ is the standard concentration of solution $(\mu \mathrm{g} / \mathrm{mL})$. The limit of detection of kresoxim-methyl when calculated using 3 times of noise-signal ratio is $1.0 \times 10^{-12} \mathrm{~g}$.

\subsection{Accuracy and Precision of the Method}

$0.02,0.20$ and $2.0 \mathrm{mg} / \mathrm{kg}$ of standard substance of kresoxim-methyl were add into blank apple sample separately, and recovery test was repeated for five times for each concentration using the constructed method. The result (table 2) has shown that when the addition was between 0.02 and 2.0 $\mathrm{mg} / \mathrm{kg}$, the average percent recovery ranged from $80 \%$ to $90 \%$, and the relative standard deviation (RSD) ranged from $0.9 \%$ to $1.3 \%$. The limit of quantitation (LOQ) was $0.02 \mathrm{mg} / \mathrm{kg}$ when using the lowest addition level method.

Table 2. The average recoveries and RSD of kresoxim-methyl in apple $(n=5)$.

\begin{tabular}{|c|c|c|c|c|c|c|c|}
\hline \multirow{2}{*}{$\begin{array}{l}\text { Spiked } \\
\text { level/mg/kg }\end{array}$} & \multicolumn{6}{|c|}{ recovery $/ \%$} & \multirow{2}{*}{ RSD $/ \%$} \\
\hline & 1 & 2 & 3 & 4 & 5 & Average & \\
\hline 0.02 & 99 & 100 & 101 & 98 & 99 & 99 & 1.0 \\
\hline 0.20 & 90 & 92 & 90 & 92 & 89 & 91 & 1.3 \\
\hline 2.0 & 80 & 80 & 79 & 81 & 79 & 80 & 0.9 \\
\hline
\end{tabular}

\subsection{Degradation Dynamics}

Table 3. Dynamic residue of kresoxim-methyl in apples from Hebei, Shandong and Anhui.

\begin{tabular}{|c|c|c|c|}
\hline \multirow{2}{*}{ Time after spraying/d } & \multicolumn{3}{|c|}{ Residue level detected/(mg/kg) } \\
\hline & Hebei (china) & Shandong (china) & Anhui (china) \\
\hline 0 & 0.648 & 0.437 & 0.528 \\
\hline 1 & 0.392 & 0.257 & 0.468 \\
\hline 3 & 0.316 & 0.230 & 0.289 \\
\hline 5 & 0.184 & 0.203 & 0.286 \\
\hline 7 & 0.034 & 0.154 & 0.262 \\
\hline 14 & 0.029 & 0.072 & 0.161 \\
\hline 21 & 0.025 & 0.060 & 0.075 \\
\hline 30 & 0.020 & 0.042 & 0.065 \\
\hline 45 & $<0.020$ & 0.032 & 0.020 \\
\hline
\end{tabular}

Refers to table 3 for the dynamic residue of kresoxim-methyl in apples from Hebei (china), Shandong (china) and Anhui (china). The origin adhesion quantities of kresoxim-methyl in apples from the three areas are 0.648, 0.438 and $0.528 \mathrm{mg} / \mathrm{kg}$ respectively. The resolution equation are $C_{t}=0.30 \mathrm{e}^{-0.115 t}, C_{t}=0.26 \mathrm{e}^{-0.0552 t}$ and $C_{t}=0.43 \mathrm{e}^{-0.0691 t}$ respectively, the correlation coefficient are $-0.8537,-0.9343$ and -0.9875 respectively, the half-lifes are $6.09 \mathrm{~d}, 12.6 \mathrm{~d}$ and $10.0 \mathrm{~d}$ respectively.

\subsection{The Terminal Residues and Risk Assessment}

Upon using $200 \mathrm{mg} / \mathrm{kg}$, the maximum recommended dose of pesticide and $300 \mathrm{mg} / \mathrm{kg}, 1.5$ times of the recommendation, the residues detected 14, 21 and 28 days after the final application of kresoxim-methyl in apples from different areas was $0.062 \sim 0.391 \mathrm{mg} / \mathrm{kg}, 0.025 \sim 0.283 \mathrm{mg} / \mathrm{kg}$ and $0.02 \sim 0.139$ $\mathrm{mg} / \mathrm{kg}$ respectively. Refers to table 4 for the average residues results in three different areas.

Table 4. The terminal residues of kresoxim-methyl in apple.

\begin{tabular}{lllll}
\hline \multirow{2}{*}{ Dosage a.i / $(\mathbf{m g} / \mathbf{k g})$} & \multirow{2}{*}{ The number of spraying } & \multicolumn{4}{l}{ Average residue/(mg/kg) } \\
\cline { 3 - 5 } & & Hebei (china) & Shandong (china) & Anhui (china) \\
\hline \multirow{2}{*}{200} & 3 & 0.194 & 0.242 & 0.115 \\
& 4 & 0.224 & 0.167 & 0.136 \\
\multirow{2}{*}{300} & 3 & 0.258 & 0.191 & 0.172 \\
& 4 & 0.266 & 0.197 & 0.182 \\
\hline
\end{tabular}

Refers to table 5 for results of the dietary risk assessment of kresoxim-methyl in apple using the maximum terminal average residual. 
Table 5. The dietary risk assessment of kresoxim-methyl in apple.

\begin{tabular}{lllllll}
\hline \multirow{2}{*}{ crowd } & \multicolumn{2}{l}{ Estimated exposure dose/[mg/(kg bw $\cdot \mathbf{d})]$} & & RQ & \\
\cline { 2 - 7 } & Hebei (china) & Shandong (china) & Anhui (china) & Hebei (china) & Shandong (china) & Anhui (china) \\
\hline Age 2-4 boy & 0.0008 & 0.0008 & 0.0006 & 0.0021 & 0.0019 & 0.0014 \\
Age 2-4 girl & 0.0009 & 0.0008 & 0.0006 & 0.0022 & 0.0020 & 0.0015 \\
Male age 18-30 & 0.0002 & 0.0002 & 0.0001 & 0.0005 & 0.0004 & 0.0003 \\
Female age 18-30 & 0.0003 & 0.0002 & 0.0002 & 0.0007 & 0.0006 & 0.0005 \\
Male age 60-70 & 0.0001 & 0.0001 & 0.0001 & 0.0004 & 0.0003 & 0.0003 \\
Female age 60-70 & 0.0002 & 0.0002 & 0.0001 & 0.0004 & 0.0004 & 0.0003 \\
\hline
\end{tabular}

\section{Conclusion}

A rapid and effective method was developed by using GC-ECD for determination of kresoxim-methyl in apple. The kresoxim-methyl dissipation rates and terminal residues in apple fields were also studied to evaluate consumer safety. The results show that the half-lives in apple were $6.09 \mathrm{~d}$ (Shijiazhuang, China), $12.6 \mathrm{~d}$ (Shandong, China) and $10.0 \mathrm{~d}$ (Anhui, China) respectively under the field condition. It can be demonstrated that after 14 days of using the appropriate amount dose set by experiment, the residual risk quotient values of kresoxim-methyl in apple are much lower than 1: thus the dietary risk of customers caused by residual in apple is extremely low if the diseases of apple are prevented and cured by experimental dose of $40 \%$ kresoxim-methyl deflocculant. Therefore, it is safe for human body when recommended amount of pesticide is used in China.

\section{References}

[1] P. Ding, H. Ma, D. Dai, et al. "Test on control strawberry powdery mildew with Kresoxim-methyl WP", Journal of Zhejiang Agricultural Sciences, 2015, vol. 56, pp. 1058-1059, 1066.

[2] L. Jin, B. Hao. "Control effect of 50\% Kresoxim-methyl WP on apple alternaria leaf spot", Journal of Hebei Agricultural Sciences, 2010, vol. 14, pp. 146-147.

[3] T. Wang, Y. Zhao, C. Wang, et al. "Testing of prevention effect for $48 \%$ Kresoxim-methyl and Tebuconazole WG to apple alternaria leaf spot", Plant protection, 2013, pp. 27-28.

[4] Y. Wang, J. Zhang, L. Shi, et al. "Report of testing of prevention effect for 55\% Kresoxim-methyl and propineb WG to apple alternaria leaf spot", Journal of Shanxi Agricultural Sciences, 2013, pp. 47-49.

[5] European Food Safety Authority, "Modification of the existing MRLs for kresoxim-methyl in blueberries and cranberries", EFSA Journal 2010, vol. 8 (12), pp. 1933.

[6] K. Yu, N. Li, X. Li, et al. "Analysis of Kresoxim-methyl by HPLC", Pesticide science and administration, 2013, vol. 34, pp. 45-47.
[7] J. Li. "Determination of Thiophanate-methyl + Kresoxim-methyl 39\% SC by HPLC", Modern Agrochemicals, 2016, vol. 15, pp. 22-24.

[8] C. Huang, X. Cheng, W. Xu, et al. "Research on analytical method of $30 \%$ Kresoxim-methyl SC by GC", Agrochemicals, 2012, vol. 15, pp. 119, 123.

[9] Q. Ge, C. Gou, R. Jiang. "Degradation behavior and safely applying technology of $30 \%$ Kresoxim-Methyl Suspensions in cucumber and soil", Journal of Anhui Agri Sci, 2014, vol. 42, pp. $7422-7425$.

[10] Q. Ge, C. Gou, R Jiang. "Determination of Kresoxim-Methyl residues in cucumber and soil by Gas Chromatography". Journal of Anhui Agri Sci, 2014, vol. 42, pp. 6690-6691.

[11] C. Chen, J. Li, X Wu. "Determ ination of Kresoxim-methyl residues in cucumber and soil by capillary Gas Chromatography", Chinese Journal of Pesticide Science, 2006, vol. 8, pp. 191-194.

[12] C. Liu, Y. Wang, K. Wan, et al. "Residue and risk assessment of kresoxim-methyl in cucumber under field conditions", Chinese Journal of Pesticide Science, 2012, vol. 14, pp. 685-688.

[13] X. Yu, L. Cai. "Residues dynamics of Kresoxim-methyl 30\% SC in wheat and soil", Agrochemicals, 2010, vol. 49, pp. 361-362, 370 .

[14] Y. Wang, D. Gong, C. Zhang, et al. "Simultaneous determination of Kresoxim - methyl and Difenoconazole residue in paddy water and soil with Gas Chromatography", Journal of Anhui Agri Sci, 2014, vol. 42, pp. 6690-6691.

[15] L. Xu, D. Gong, B. Liu, et al. "Simultaneous determination of Fenoxanil and Kresoxim - methyl residue in paddy field", Crop Research, 2013, vol. 27, pp. 151-154.

[16] Institute of Quality Standards and Testing Technology for Agro-Products, Chinese Academy of Agricultural Science. Risk Assessment for Quality and Safety of Agro-foods: Principles, Methodologies and Applications, Beijing, Standards Press of China, 2007.

[17] S. Jin. The Tenth Report of Nutrition and Healthy Status for China Residents: Nutrition and Healthy Status of Annual 2002, Beijing, People's Medical Publishing House, 2008. 